\title{
Prevalence and Potential Determinants of Aggregate Anthropometric Failure among Pakistani Children: Findings from a Community Health Survey
}

\author{
Oluwafemi Samson Balogun ${ }^{1} \mathbb{D}$, Atta Muhammad Asif ${ }^{2} \mathbb{D}$, Muhammad Akbar $^{2} \mathbb{D}$, Christophe Chesneau $^{3}$ \\ and Farrukh Jamal ${ }^{4, *}$
}

check for

updates

Citation: Balogun, O.S.; Asif, A.M.; Akbar, M.; Chesneau, C.; Jamal, F.

Prevalence and Potential

Determinants of Aggregate

Anthropometric Failure among Pakistani Children: Findings from a Community Health Survey. Children 2021, 8, 1010. https://doi.org/

$10.3390 /$ children 8111010

Academic Editor: Tuan Nguyen

Received: 2 September 2021

Accepted: 1 November 2021

Published: 4 November 2021

Publisher's Note: MDPI stays neutral with regard to jurisdictional claims in published maps and institutional affiliations.

Copyright: (c) 2021 by the authors. Licensee MDPI, Basel, Switzerland. This article is an open access article distributed under the terms and conditions of the Creative Commons Attribution (CC BY) license (https:// creativecommons.org/licenses/by/ $4.0 /)$.
1 Department of Northern Europe, School of Computing, University of Eastern Finland, 70211 Kuopio, Finland; samson.balogun@uef.fi

2 Department of Mathematics and Statistics, Faculty of Basic and Applied Sciences, International Islamic University, Islamabad 44000, Pakistan; atta.msst18@iiu.edu.pk (A.M.A.); muhammad.akbar@iiu.edu.pk (M.A.)

3 Department of Mathematics, LMNO, University of Caen, 14032 Caen, France; christophe.chesneau@unicaen.fr

4 Department of Statistics, The Islamia University Bahawalpur, Bahawalpur 61300, Pakistan

* Correspondence: farrukh.jamal@iub.edu.pk

\begin{abstract}
Malnutrition among children is an important public health problem in Pakistan. Conventional indicators (stunting, wasting and underweight) are well known. However, there is a need for aggregate indicators in this perspective. The goal of this study is to assess the prevalence and trends of malnutrition among Pakistani children under the age of five using the so-called composite index of anthropometric failure (CIAF), a tool for calculating the whole aggregate burden of malnutrition. The data were extracted from the Pakistan Demographic and Health Survey 2012-2013. Mothers' education and socioeconomic statuses (SES) were assessed as important factors in malnutrition. Chi-squared analysis was used to check the bivariate association, and multiple logistic regression was used to identify the significant correlates of child malnutrition. Moreover, multiple correspondence analysis (MCA) was applied to strengthen the use of CIAF as an outcome variable. The study looked at 3071 children under the age of five, with $52.2 \%$ of them falling into the CIAF. Children of educated mothers had $43 \%$ fewer odds of being malnourished (OR (Odd Ratio) $=0.57,95 \%$ CI (Confidence Interval $=0.44-0.73$ ). Additionally, a decreasing trend in malnutrition was found with increasing SES. There is a need to improve maternal education. Such programs focusing on increasing women's autonomy in making home decisions should be established. Furthermore, long-term interventions for improving home SES and effective nutritional methods should be examined. For policymakers, the use of CIAF is suggested since it provides an estimate of the entire burden of undernutrition.
\end{abstract}

Keywords: child malnutrition; CIAF; multivariate logistic regression; mother's education; socioeconomic status; MCA

\section{Introduction}

The nutritional status of a population has a significant impact on a country's socioeconomic progress. The first few years of life are crucial to a child's mental and physical development. However, these years are set apart by micronutrient inadequacies that interferes with good growth. In addition, children of this age are not able to fight off preventable diseases [1]. As a result, nutrition is regarded as one of the most important components of the 2015 Sustainable Development Goals (SDGs). Poor nutrition can lead to an increase in the risk of infection, morbidity, and death, as well as a decline in mental development in children during their early years [2]. Additionally, it is considered that children are more vulnerable to malnutrition, and thus, child growth is an important factor in malnutrition in populations. 
In 2016, 155 million children were stunted, 41 million were overweight, and 52 million were wasting, according to a joint report by UNICEF, WHO, and the World Bank group [3]. About half of these youngsters live in Pakistan, India, and Bangladesh, three South Asian countries [4]. Thus, malnutrition is a serious issue in many countries.

Pakistan is the world's sixth most populous country and is placed it 124th out of 132 nations due to a $45 \%$ prevalence of stunting and 106th out of 130 countries due to an $11 \%$ frequency of childhood wasting [5]. In Pakistan, $0.7 \%$ of general government spending is committed to nutrition-sensitive interventions, which is lower than in other countries in the area, such as Nepal and Bangladesh, where the allocations are $3.1 \%$ and $2.1 \%$, respectively [4].

Generally, child malnutrition is measured through conventional anthropometric indices (stunting, wasting, and underweight) in the literature [6,7]. These metrics, on the other hand, describe various aspects of malnutrition and overlap. For example, underweight is made up of both wasting and stunting, yet there is no distinction between them [8]. Despite the use of conventional indicators being frequent in the literature [9,10], some authors have pointed out that the use of these indicators could not determine the overall burden of under nutrition [11]. Therefore, there is need to use a single indicator that may capture the magnitude of nutritional status and identify the affected part of the population. According to Peter Svedberg, the use of conventional measures described above is not appropriate because they are not sufficient for the measurement of the overall prevalence of malnutrition [12]. He also claims that a new indicator that includes malnourished children is needed, and he proposes the composite index of anthropometric failure as a new measure of child nutrition (CIAF). This newly proposed index (i.e., CIAF) is based on conventional anthropometric indices through forming different failure groups (which are described in the methods section). A number of studies in the literature have used this proposed indicator (i.e., CIAF) in different parts of the world, such as $[2,8,11,13-15]$ and have recommended this indicator as an alternative measure of malnutrition. However, in Pakistan, no such study has been conducted so far that can measure the prevalence of malnutrition through CIAF, as per the author's knowledge. Therefore, this study follows Svedberg's theory and uses this relatively robust alternative measure to examine the prevalence and association of under-five child malnutrition with other socioeconomic and demographic risk factors in Pakistan. Further, we hypothesize that CIAF gives a more accurate assessment of malnutrition among children than conventional measures.

\section{Materials and Methods}

\subsection{Data Source}

Nationally representative cross-sectional data from the Pakistan Demographic and Health Survey (PDHS) 2012-2013 were used for analysis (available at measuredhs.com (accessed on 14 August 2021)). Using a two-stage, stratified selection technique, a sample of 14,000 households was chosen. Using the probability proportional to size technique, 500 primary sampling units (252 rural and 248 urban) were selected in the first step. In the second stage, a systematic sampling process was used to choose 28 households from each primary sampling unit (a predefined number). In total, 14,569 eligible women of ages 15-49 years were selected for interview, and of these, 13,558 women were successfully interviewed. Within five years of the study, these mothers had given birth to a total of 11,763 living children. However, this analysis remains limited to 3071 live-born children of age less than 5 years with valid anthropometric information. The children whose nutritional indicators information was not present/measured were excluded from the analysis. Further details can be seen elsewhere [1].

\subsection{Outcome Variable}

The new policy-relevant anthropometric indicator of malnutrition, i.e., CIAF, is the primary outcome variable in this study. A child is termed stunted, wasted, or underweight if his or her height-for-age Z-score (HAZ), weight-for-height Z-score (WHZ), or weight- 
for-age Z-score (WAZ) are all less than two standard deviations from the WHO reference population median. Further details and guidelines about these growth standards can be seen elsewhere [16]. Following [17], we have categorized all children into seven groups (see Table 1 for details). A child who did not fall into any of the anthropometric failures was classified as "not malnourished" and was coded as " 0 ", and a child is considered to be malnourished if he/she is suffering from any of the anthropometric failure groups, and is coded as " 1 ". Hence, the response variable is of binary nature.

Table 1. For the creation of the response variable, different groups were used (CIAF).

\begin{tabular}{cccccc}
\hline Group & Characterization & Wasting & Stunting & Underweight & N (\%) \\
\hline A & No failure & N & N & N & $1467(47.8)$ \\
B & Wasting only & $\mathrm{Y}$ & $\mathrm{N}$ & $\mathrm{N}$ & $92(3.0)$ \\
$\mathrm{C}$ & Wasting and Underweight & $\mathrm{Y}$ & $\mathrm{N}$ & $\mathrm{Y}$ & $88(2.9)$ \\
$\mathrm{D}$ & Wasting, Stunting and Underweight & $\mathrm{Y}$ & $\mathrm{Y}$ & $\mathrm{Y}$ & $139(4.5)$ \\
$\mathrm{E}$ & Stunting and Underweight & $\mathrm{N}$ & $\mathrm{Y}$ & $\mathrm{Y}$ & $545(17.7)$ \\
$\mathrm{F}$ & Stunting only & $\mathrm{N}$ & $\mathrm{Y}$ & $\mathrm{N}$ & $696(22.7)$ \\
$\mathrm{Y}$ & Underweight only & $\mathrm{N}$ & $\mathrm{N}$ & $\mathrm{Y}$ & $44(1.4)$ \\
\hline
\end{tabular}

CIAF $(B+C+D+E+F+Y)=52.2 \%, N=$ No and $Y=$ Yes.

\subsection{Explanatory Variables}

A number of indicators were retrieved from the PDHS data (KR-File) and recategorized using the UNICEF conceptual framework for causes of malnutrition [18] (when this categorized operation is necessary). These indicators include regions of residence (categorized as Punjab, Sindh, Khyber Pakhtunkhaw, Blochistan, Gilgit-Baltistan, Islamabad), type of residence (rural/urban), mother's education (categorized as no education, primary, secondary, higher), father's education (categorized as no education, primary, secondary, higher), gender of the child (male/female), presence of other child/children of age $<5$ years (yes/no), vaccination status (categorized as nonvaccinated, partially vaccinated and fully vaccinated), mother's age at first birth (categorized as less than 20 years, 21-30 years, more than 30 years), household wealth index (categorized as poorest, poor, middle, rich, richest), type of water facility (categorized as improved and unimproved) and type of toilet facility (categorized as improved and unimproved).

The socioeconomic status (SES) (in the PDHS data this variable is labeled as wealth index (v190)) was computed by employing the principal component analysis (PCA) technique on a set of household durables (table, chair or bench, watch, radio, television, bicycle, telephone, etc.), housing characteristics such as having electricity, type of source of drinking water, access to a sanitation facility, availability of cooking fuel, main roof material, main wall material, floor material items. This proximate variable was then divided into socioeconomic quintiles: SES-I (poorest), SES-II (poor), SES-III (middle), SES-IV (rich) and SES-V (richest), based on the factor scores (PDHS report, 2013). This indicator may serve as a household wealth status and is consistent with income and expenditure measures [19]. Sahn and Stifel [20] preferred the use of an asset-based wealth index for measuring living standards and capabilities such as nutrition and health. The type of toilet facility and type of water facility were categorized following the procedure adopted by [21]. Children who have not taken even a single dose of any vaccine were considered as "nonvaccinated", those who have taken some doses but not all, were considered as "partially vaccinated" and those who have taken all the prescribed doses of all vaccines were considered "fully vaccinated".

\subsection{Statistical Analysis}

The statistical analysis was conducted in the following manner. First, the bivariate association between the outcome variable and different exposure variables was tested using a chi-squared test of association. Second, a multiple correspondence analysis (MCA) was performed to capture the relationship between the six categories of conventional measures 
(stunting (yes/no), wasting (yes/no) and underweight (yes/no). Finally, multiple logistic regression was performed to find the significant factors CIAF, which is described as follows.

Logistic regression is a popular modeling approach when the response variable is dichotomous. As the dependent variable is of dichotomous type, the possible outcomes are either "being malnourished" (taken as 1 ) or "being nourished" (taken as 0 ), therefore the magnitude of the relationships of the determinants to carrier outcomes of the children will be analyzed using the Logistic Regression models for the dependent variable "being malnourished".

Consider a general $(k+1)$ variable equation:

$$
Y_{i}^{*}=\beta^{\prime} X_{i}+U_{i} \text { for } i=1,2 \ldots n
$$

Here, we do not observe $Y_{i}^{*}$, instead, we observe the binary variable:

We can write it as

$Y_{i}=\left\{\begin{array}{c}1 \text { if } Y_{i}^{*}=\beta^{\prime} X_{i}+U_{i}>0 \\ 0 \text { otherwise }\end{array}\right.$, Note that probability of the observed $y_{i}$ being one can be written as

$$
\begin{gathered}
\operatorname{Pr}\left(y_{i}=1\right)=\operatorname{Pr}\left(Y_{i}^{*}>0\right) \\
\operatorname{Pr}\left(U_{i}>-\beta^{\prime} X_{i}\right)=1-F\left(-\beta^{\prime} X_{i}\right)=F\left(\beta^{\prime} X_{i}\right)
\end{gathered}
$$

If we replace $F\left(\beta^{\prime} X_{i}\right)$ with $\wedge\left(\beta^{\prime} X_{i}\right)$

Then, we obtain the logit model. Here, $\wedge\left(\beta^{\prime} X_{i}\right)$ is the logistic cumulative function.

$$
\wedge\left(\beta^{\prime} X_{i}\right)=\frac{e^{X^{\prime} \beta}}{1-e^{X^{\prime} \beta}}
$$

In the observations, we have " $n$ " cases of zeros and ones with probability of $F\left(\beta^{\prime} X_{i}\right)$ for ones and $\left(1-F\left(\beta^{\prime} X_{i}\right)\right)$ for zeros. Thus, the likelihood function is

$$
\operatorname{Pr}\left(Y_{1}=0, Y_{2}=1, \ldots \ldots \ldots, Y_{n}=0\right)=\prod_{y_{i=0}}\left[1-F\left(\beta^{\prime} X_{i}\right)\right] \prod_{y_{i=1}}\left[F\left(\beta^{\prime} X_{i}\right)\right]
$$

Or

$$
L=\prod_{i}\left[\left[1-F\left(\beta^{\prime} X_{i}\right)\right]^{1-y_{i}}\left[F\left(\beta^{\prime} X_{i}\right)\right]^{y_{i}}\right]
$$

Taking logs on both sides, we have

$$
\boldsymbol{L n}(L)=\sum_{i}\left[\left(1-y_{i}\right) \ln \left(1-F\left(\beta^{\prime} X_{i}\right)\right)+y_{i} \ln \left(F\left(\beta^{\prime} X_{i}\right)\right)\right]
$$

This is the log likelihood function, and for logistic case it becomes

$$
\operatorname{Ln}(L)=\sum_{i}\left[\left(1-y_{i}\right) \ln \left(1-\wedge\left(\beta^{\prime} X_{i}\right)\right)+y_{i} \ln \wedge\left(\beta^{\prime} X_{i}\right)\right]
$$

Or

$$
\operatorname{Ln}(L)=\sum_{y i=0} \ln \left(1-\wedge\left(\beta^{\prime} X_{i}\right)\right)+\sum_{y_{i=1}} \ln \left(\wedge\left(\beta^{\prime} X_{i}\right)\right)
$$

where $\beta^{\prime}=\left(\beta_{0}, \beta_{1}, \beta_{2}, \ldots \ldots . \beta_{k}\right)$ are the model parameters and $X^{\prime}=\left(X_{0}, X_{1}, X_{2}, \ldots \ldots \ldots X_{k}\right)$ with $X_{0}=1$ are the explanatory variables.

Relative odd ratios will be found to see that how the prevalence of employment varies with a unit change in a specific independent variable, keeping the remaining variables as constant for the data. Since

$$
\operatorname{Ln}\left(o d d_{2}\right)-\operatorname{Ln}\left(o d d_{1}\right)=\operatorname{Ln}\left(\frac{o d d_{2}}{o d d_{1}}\right)=\mathrm{B}
$$

where

$$
o d d_{2}=P(\text { malnourished })
$$


and

$$
\begin{gathered}
o d d_{1}=P(\text { nourished }) \\
\text { odd }_{2} / \text { odd }_{1}=\exp (B), \text { So } \\
\text { Odd }- \text { Ratio }=\exp (B)
\end{gathered}
$$

Model adequacy was checked by using the Hosmer-Lemeshow test of goodnessof-fit and receiver operating characteristic (ROC) analysis. Hosmer-Lemeshow statistic follows a chi-squared distribution on ( $\mathrm{g}$-2) degrees of freedom, where ' $\mathrm{g}$ ' denotes the number of groups (here $g=10$ ). Following Hosmer-Lemeshow guidelines, variables were selected for multivariate analysis if they were found to be significant at a $25 \%$ level of significance in bivariate analysis. Further details about the logistic regression procedure and model validation can be seen in [22,23]. The statistical software Stata (version 14.0: Stata Corporation, College Station, TX, USA) was used for data cleansing and analysis.

\section{Results}

Characteristics of the study population: this analysis is based on data of 3071 5-yearold children. Out of these, $49.3 \%$ were female and $56.7 \%$ were living in rural areas. However, there exist disparities between rural and urban areas regarding child malnutrition. The prevalence of children falling into CIAF remained high for both male and female children in the rural areas (Figure 1). A large number of mothers were uneducated (52.3\%); however, $34 \%$ of the fathers had secondary education. The prevalence of malnutrition among noneducated rural women was highest $(37.2 \%)$ and this percentage shrank to $2.8 \%$ for children of educated women in rural areas. The overall position in the case of urban mothers is better. However, $15.1 \%$ of the children of urban non-educated mothers fall into the CIAF index, which is the highest among urban children (Figure 2). A major portion of the study sample contains the residents of Punjab (33.2\%) and Sindh (22.9\%). These regions consist of the highest burden of malnourished children ( $28.2 \%$ and $27.8 \%$, respectively). Seventy-six percent of households have more than one child under five years old. A total of $634(20.6 \%)$ households fell into the poorest wealth index (SES-I), while 19.9\% of the households fell into the richest index (SES-V). Seventy-nine percent of the mothers were not working, while $50.3 \%$ were less than 20 years old at the time of their first birth. A total of $2567(83.6 \%)$ of the households drank improved water, while $70 \%$ of the households had access to improved toilet facilities. Further details can be seen in (Table 2).

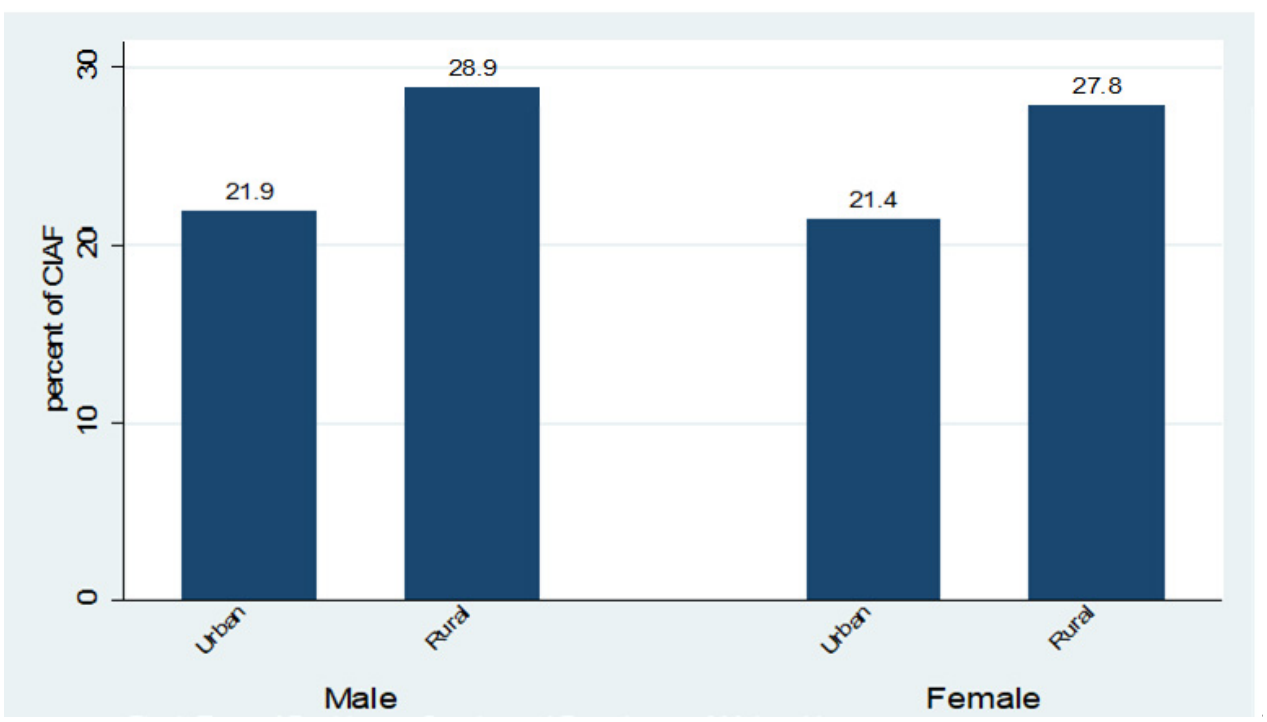

Figure 1. Type of Residence, Gender and Prevelance of Malnutrition. 


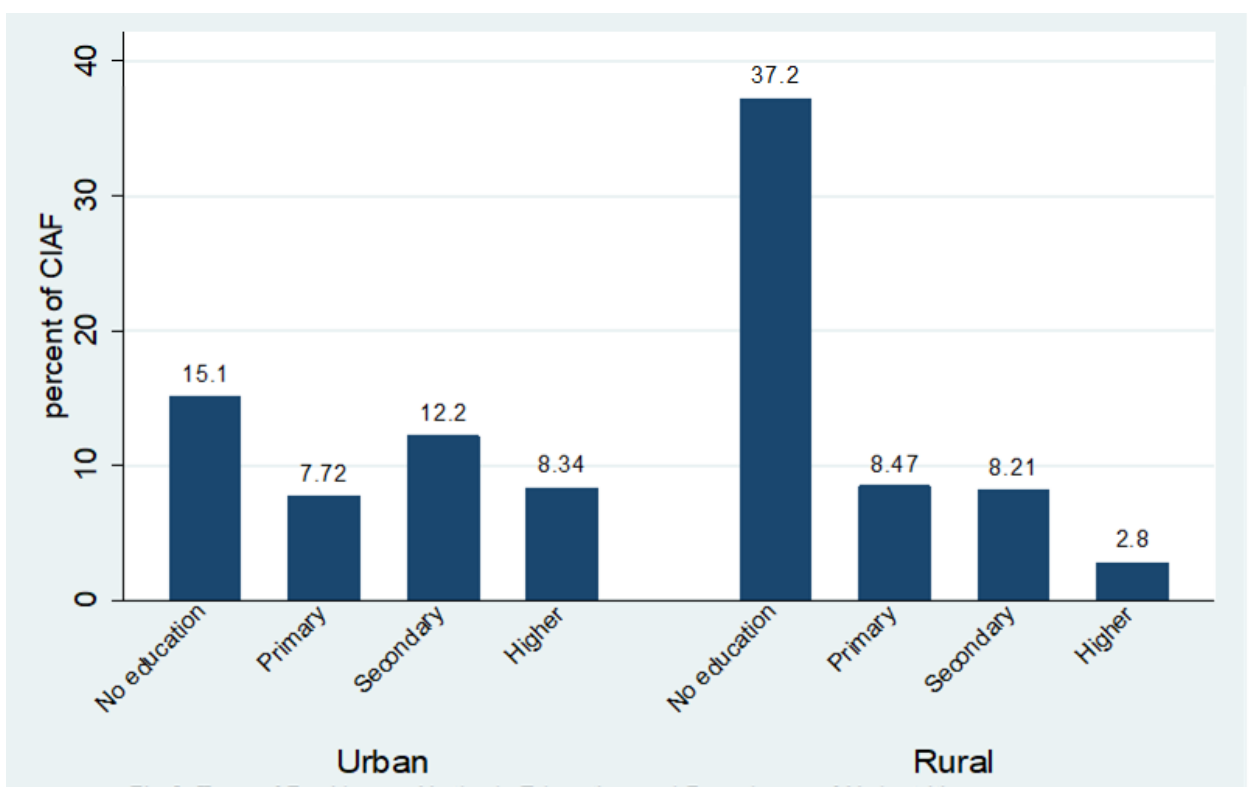

Figure 2. Type of Residence, Mother's Education and Prevelance of Mulnutrition.

Table 2. Prevalence and bivariate association for child malnutrition by exposure variables.

\begin{tabular}{|c|c|c|c|c|}
\hline Exposure Variables & $\begin{array}{c}\text { Yes } \\
\text { N (\%) }\end{array}$ & $\begin{array}{c}\text { Malnourish } \\
\text { No } \\
\text { N (\%) }\end{array}$ & $\begin{array}{c}\text { Total } \\
\text { N (\%) }\end{array}$ & Chi-Squared Value \\
\hline \multicolumn{5}{|l|}{ Regions } \\
\hline Punjab & $453(28.2)$ & $565(38.51)$ & 1018 (33.2) & \multirow{6}{*}{213.24 * } \\
\hline Sindh & $446(27.8)$ & $258(17.6)$ & $704(22.9)$ & \\
\hline Khyber Pakhtunkhaw & $245(15.3)$ & $296(20.2)$ & $541(17.6)$ & \\
\hline Blochistan & $243(15.2)$ & $49(03.3)$ & $292(09.5)$ & \\
\hline Gilgit Baltistan & $144(09.0)$ & $157(10.7)$ & $301(09.8)$ & \\
\hline Islamabad & $73(04.6)$ & $142(09.7)$ & $215(07.0)$ & \\
\hline \multicolumn{5}{|l|}{ Residence Type } \\
\hline Urban & $625(39.0)$ & $705(48.0)$ & $1330(43.3)$ & \multirow{2}{*}{$25.80 *$} \\
\hline Rural & $979(61.0)$ & $762(52.0)$ & $1741(56.7)$ & \\
\hline \multicolumn{5}{|l|}{ Mother's Education } \\
\hline No Education & $1003(62.5)$ & $603(41.1)$ & $1606(52.3)$ & \multirow{4}{*}{191.42 * } \\
\hline Primary & $268(16.7)$ & $229(15.6)$ & $497(16.2)$ & \\
\hline Secondary & $219(13.7)$ & $407(27.7)$ & $626(20.4)$ & \\
\hline Higher & $114(07.1)$ & $228(15.5)$ & $342(11.1)$ & \\
\hline \multicolumn{5}{|l|}{ Father Education } \\
\hline No Education & $578(36.0)$ & $334(22.8)$ & 912 (29.7) & \multirow{4}{*}{86.02 * } \\
\hline Primary & $258(16.1)$ & $197(13.4)$ & $455(14.8)$ & \\
\hline Secondary & $485(30.2)$ & $560(38.2)$ & $1045(34.0)$ & \\
\hline Higher & $283(17.6)$ & $376(25.6)$ & $659(21.5)$ & \\
\hline \multicolumn{5}{|l|}{ Gender of Child } \\
\hline Male & $848(52.9)$ & $710(48.4)$ & $1558(50.7)$ & \multirow{2}{*}{$6.12 *$} \\
\hline Female & $756(47.1)$ & $757(51.6)$ & $1513(49.3)$ & \\
\hline \multicolumn{5}{|l|}{ Vaccination } \\
\hline Not vaccinated & 173(10.8) & $91(06.2)$ & $264(08.6)$ & \multirow{3}{*}{$39.48 *$} \\
\hline Partially vaccinated & $909(56.7)$ & $763(52.0)$ & $1672(54.4)$ & \\
\hline Fully vaccinated & $522(32.5)$ & $613(41.8)$ & $1135(37.0)$ & \\
\hline
\end{tabular}


Table 2. Cont.

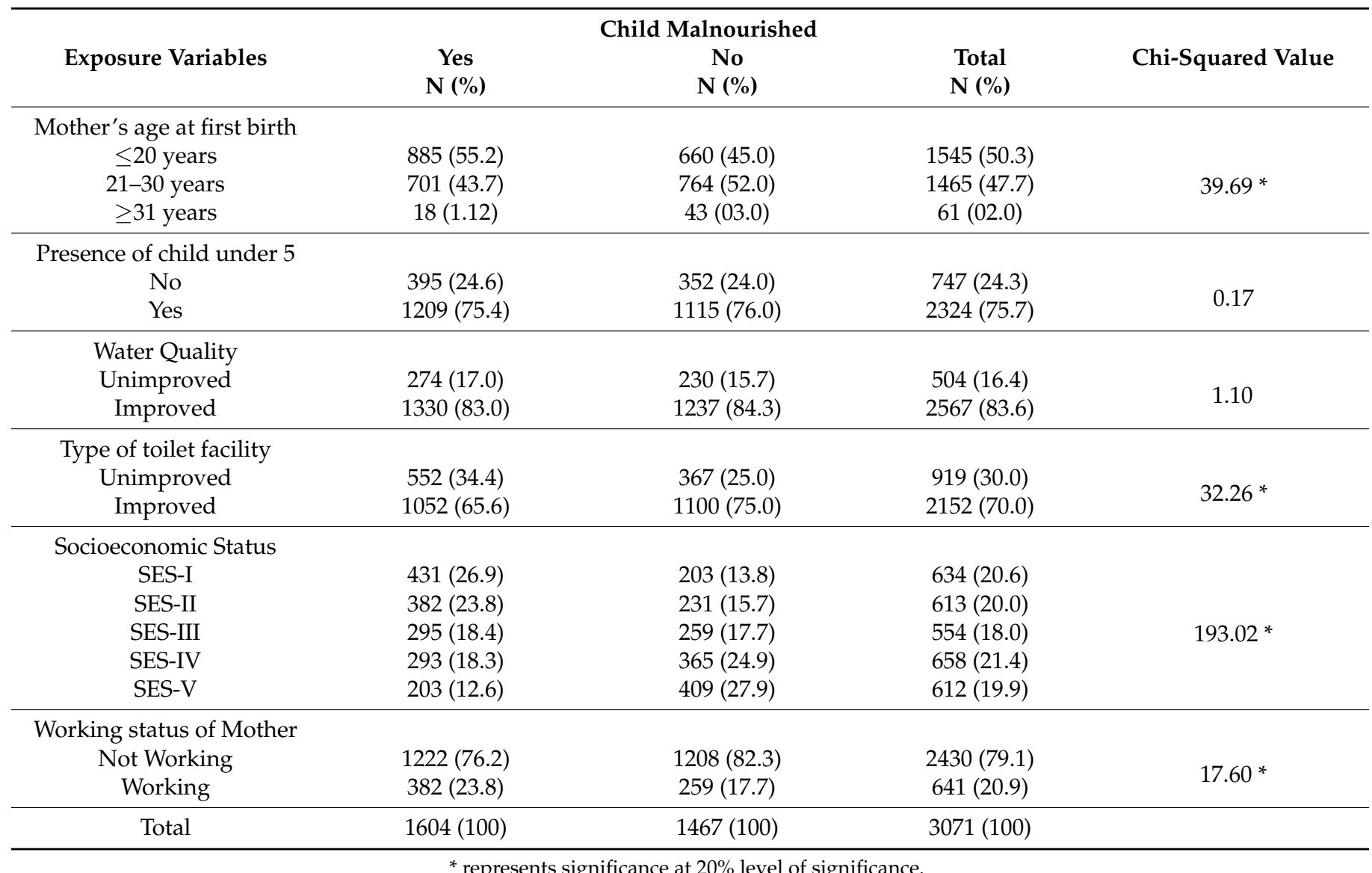

* represents significance at $20 \%$ level of significance.

Status of malnutrition in the study population: Table 1 presents the prevalence of all groups of nutritional status. According to the conventional anthropometric measures, $45 \%$ (1380 out of 3071 ) of the children were stunted, $10.4 \%$ (319 out of 3071) were wasted, and $26.6 \%$ (816 out of 3071 ) were underweight, while $52.2 \%$ (1604 out of 3071 ) of the children fell into anthropometric failure. Accordingly, $4.5 \%$ of the children fall into all three and $27.1 \%$ of the children fall into a single anthropometric failure.

Multiple Correspondence Analyses: A total of about $74 \%$ of the inertia is explained by the first two dimensions. Points of the different categories of the same variables are clearly separated (Figure 3). Stunting and wasting appeared in the second and fourth quadrants of the plot, indicating that they are not associated. Underweight lies on the borderline between the second and fourth quarter, indicating that it is associated with both stunting and wasting, which strengthens Svedberg's theory of using an aggregate index to measure malnutrition instead of conventional measures.

Factors associated with CIAF: The multiple logistic regression model presented in (Table 3) showed that region of residence, mother's education, gender, mother's age at first birth, and socioeconomic status of the household were significantly associated with the composite index. However, residence type, father's education, vaccination, mother's working status, and type of toilet facility had no significant association with CIAF. 


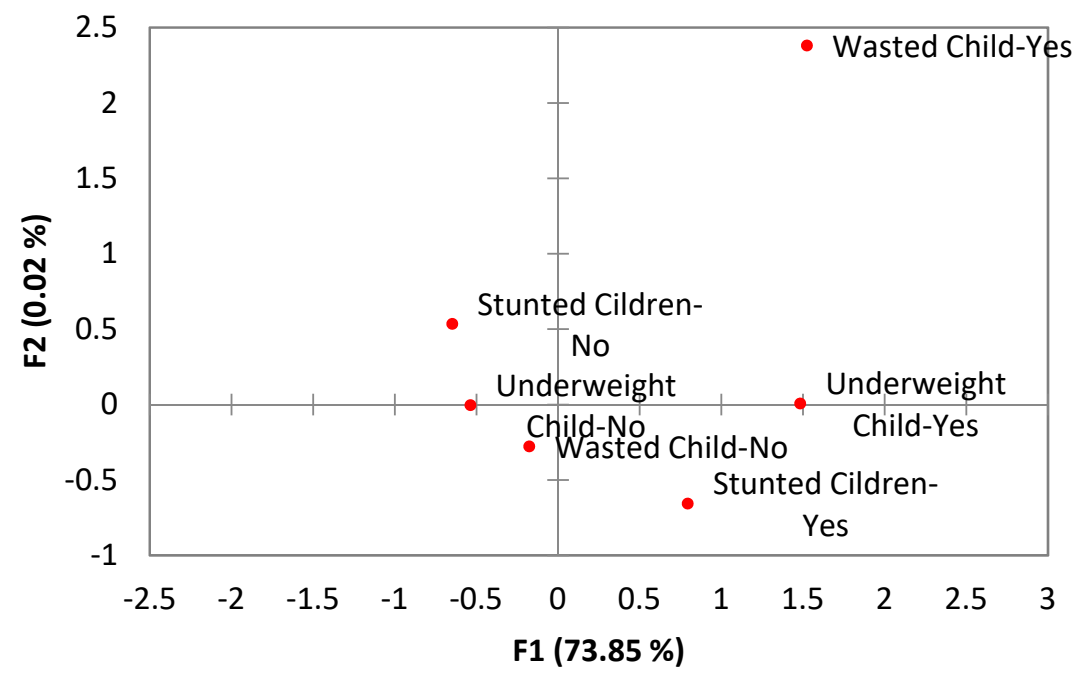

Figure 3. Multiple correspondence analyses of conventional measures (Stunting, wasting and underweight).

Table 3. Logistic regression analysis of factors associated with child malnutrition (CIAF).

\begin{tabular}{|c|c|c|c|}
\hline Exposure Variables & \multicolumn{2}{|c|}{ Odd Ratios (95\% CI) } & $p$-Value \\
\hline \multicolumn{4}{|l|}{ Regions } \\
\hline Punjab & \multicolumn{2}{|c|}{1} & \\
\hline Sindh & $1.98^{* *}$ & $(1.59-2.46)$ & $<0.001$ \\
\hline Khyber Pakhtunkhaw & 0.92 & $(0.73-1.16)$ & $<0.476$ \\
\hline Blochistan & $5.20 * *$ & $3.647 .42)$ & $<0.001$ \\
\hline Gilgit Baltistan & 0.81 & $(0.59-1.11)$ & $<0.187$ \\
\hline Islamabad & 0.96 & $(0.681 .34)$ & $<0.824$ \\
\hline \multicolumn{4}{|l|}{ Residence Type } \\
\hline Urban & 1 & & \\
\hline Rural & 0.95 & $(0.78-1.15)$ & $<0.618$ \\
\hline \multicolumn{4}{|l|}{ Mother's Education } \\
\hline No Education & 1 & & \\
\hline Primary & 0.99 & $(0.78-1.25)$ & $<0.946$ \\
\hline Secondary & $0.57^{* *}$ & $(0.44-0.73)$ & $<0.001$ \\
\hline Higher & $0.59 * *$ & $(0.42-0.83)$ & $<0.002$ \\
\hline \multicolumn{4}{|l|}{ Father Education } \\
\hline No Education & 1 & & \\
\hline Primary & 0.98 & $(0.76-1.25)$ & $<0.855$ \\
\hline Secondary & 0.85 & $(0.68-1.05)$ & $<0.128$ \\
\hline Higher & 0.95 & $(0.73-1.23)$ & $<0.700$ \\
\hline \multicolumn{4}{|l|}{ Gender of Child } \\
\hline Male & 1 & & \\
\hline Female & $0.82 * *$ & $(0.70-0.95)$ & $<0.010$ \\
\hline
\end{tabular}


Table 3. Cont.

\begin{tabular}{|c|c|c|c|}
\hline Exposure Variables & \multicolumn{2}{|c|}{ Odd Ratios (95\% CI) } & $p$-Value \\
\hline \multicolumn{4}{|l|}{ Vaccination } \\
\hline Not vaccinated & 1 & & \\
\hline Partially vaccinated & 0.83 & $(0.61-1.12)$ & $<0.227$ \\
\hline Fully vaccinated & 0.97 & $(0.70-1.34)$ & $<0.868$ \\
\hline \multicolumn{4}{|l|}{ Mother's age at first birth } \\
\hline$\leq 20$ years & 1 & & \\
\hline $21-30$ years & 0.87 & $(0.74-1.03)$ & $<0.103$ \\
\hline$\geq 31$ years & $0.46^{* *}$ & $(0.24-0.84)$ & $<0.012$ \\
\hline \multicolumn{4}{|l|}{ Working Mother } \\
\hline No & 1 & & \\
\hline Yes & 0.98 & $(0.80-1.21)$ & $<0.87$ \\
\hline \multicolumn{4}{|l|}{ Type of toilet facility } \\
\hline Unimproved & 1 & & \\
\hline Improved & 1.15 & $(0.93-1.40)$ & $<0.189$ \\
\hline \multicolumn{4}{|l|}{ Socioeconomic Status } \\
\hline SES-I & 1 & & \\
\hline SES-II & 1.06 & $(0.81-1.38)$ & $<0.681$ \\
\hline SES-III & $0.75 *$ & $(0.55-1.02)$ & $<0.063$ \\
\hline SES-IV & $0.56^{* *}$ & $(0.39-0.78)$ & $<0.001$ \\
\hline SES-V & $0.39 * *$ & $(0.26-0.58)$ & $<0.001$ \\
\hline
\end{tabular}

Children of the Sindh region were at double the risk $(\mathrm{OR}=1.98,95 \% \mathrm{CI}=1.59-2.46)$ and children of the Baluchistan region were at about five times a higher risk $(\mathrm{OR}=5.20$, $95 \% \mathrm{CI}=3.64-7.42)$ of malnutrition compared to the residents of the Punjab region. Compared to uneducated mothers, the children of educated mothers (at least secondary education) had $43 \%$ lower odds of being malnourished ( $\mathrm{OR}=0.57,95 \% \mathrm{CI}=0.44-0.73$ ). Female children had $18 \%$ lower chances of falling within the anthropometric failure in$\operatorname{dex}(\mathrm{OR}=0.82,95 \% \mathrm{CI}=0.70-0.95)$. Regarding mother's age at first birth, children of mothers aged 21-30 years had 13\% lower chances of being malnourished ( $\mathrm{OR}=0.87$, $95 \% \mathrm{CI}=0.74-1.00)$, while for mothers aged more than 30 years, the risk of undernutrition remained about half $(\mathrm{OR}=0.46,95 \% \mathrm{CI}=0.24-0.84)$. Moreover, the children of households with higher socioeconomic status were less likely to fall within the index compared with households with lower SES (SES-V; OR $=0.39,95 \% \mathrm{CI}=0.26-0.58$, and SES-IV; OR $=0.56,95 \% \mathrm{CI}=0.39-0.78$ ). The results further demonstrated a rejection of the null hypothesis of the Hosmer-Lemeshow test of goodness-of-fit, indicating that the model is adequate (Hosmer-Lemeshow chi2 $=2.52$; $p$-value $=0.96$ ). Moreover, the area under the receiver operating characteristic $(\mathrm{ROC})$ curve $($ area $=0.71)$ also confirmed an acceptable discrimination.

\section{Discussions}

In underdeveloped nations where the majority of the population is malnourished, assessing the nutritional status of children under the age of five is crucial [13]. According to the CIAF, the prevalence of stunting, wasting, and underweight were $45 \%, 11 \%$, and $27 \%$, respectively, while the prevalence of undernutrition was $52 \%$ among the studied sample.

According to the CIAF, the findings of this study are better than those of other countries, such as Ethiopia [8], and somewhat better than India [24]. This percentage is also high compared with the results stated in the PDHS' (for the cycle 2012-2013) last report. This distinction might be because of the estimation strategies. However, the writings [25,26], and additionally the correspondence analysis of customary anthropometric measures, demonstrated that underweight is related to both stunting and wasting, which likewise 
reinforces the possibility of different investigations that CIAF provides a better gauge of children's malnutrition compared with traditional markers [2].

There is a strong link between children's nutritional status and their geographic location. Balochistan, followed by Sindh, is at a significant risk of falling into demographic failure. Seasonal food instability, cultural norms, and insufficient water and sanitation facilities may all contribute to this.

Different dimensions of gender discrimination have already been discussed in several research studies. Some of them demonstrated that girls are at greater risk, such as $[27,28]$ compared to boys, while others revealed that male children are more likely to be malnourished [10,29]. However, some studies showed an absence of gender discrimination in this regard, such as [30,31]. This analysis revealed that female children have a lower chance of being malnourished, which is in line with results of other studies, such as [32] for Tanzania and [33] for West Africa. Few studies have shown that children in urban areas have better nutritional status compared with children in rural areas $[14,29,34]$. The outcomes of this examination uncovered no critical relationship between CIAF and any type of place of residence, which is similar to the results of some other studies, such as [35] for Bangladesh and [33] for West Africa. The mother's age at first birth also showed a significant association with CIAF, which strengthens the hypothesis that older mothers may have better knowledge about feeding practices and other health measures of their children.

One of the key determinants of child malnutrition is parental education, especially mother's education. Much of the literature has demonstrated that improved maternal education might be one of the defensive measures against children's poor nutritional status $[10,11,36-38]$. This study also highlighted the fact that children of literate mothers (at least secondary education) were less likely to fall into anthropometric failure. Mother's education may also be considered as a proxy for mother's empowerment. A woman's improved educational status may be considered as an increase in autonomy in family decision making. Hence, mother's education can act as a mediator between the nutritional status of the child and decision-making autonomy [35]. Another explanation is that in poor nations, an educated mother can gain better-paying jobs and greater influence [29], which benefits the child's health in the long term. Thus, we may conclude that the mother's better educational level might be considered a measure of protection against childhood undernutrition. Many studies have discussed the association between household socioeconomic status and child health, such as $[7,33,39]$.

The wealth index was used as a proxy measure of socioeconomic status to access the relationship with CIAF. It was found that the children of SES-IV and SES-V were less likely to fall into the CIAF which is in the line with other studies on the topic $[7,28,29,31,40]$.

This may be due to the fact that children from higher-income families may have better access to good, nutritious food, whereas children from lower-income families are more likely to succumb to malnutrition due to insufficient food, high infection risk, and lack of access to basic requirements [34]. Parents from wealthy families are more likely to be educated than those from poor families, resulting in better access to food, a higher proportion of resources allocated to children's welfare, and a higher living standard [41], all of which result in better health care for their children. Another study examining the interaction between SES and maternal education in connection to child's health, found that the impact of better education for the mother turned out to be more defensive for the children of rich families, while the father's education works independently of SES and is considered as a protective element [42].

The results and their interpretations of this study should, however, be considered in light of a few limitations. First, the use of cross-sectional data only allows us to investigate associations, so it is difficult to investigate cause and effect relationships. Second, the use of indirect measures of a household's wealth status may be criticized. However, this indicator may serve as a household wealth status and is consistent with income and expenditure measures [19]. Fourth, the findings of this study rely on self-reported data, which may cause recall bias. 


\section{Conclusions}

Despite the limitations mentioned above, this study has identified the most important factors influencing child malnutrition, which could have a substantial impact on the literature on the relationship between CIAF and socioeconomic and demographic characteristics. The educational condition of parents, particularly the mother's education, must be improved. Such programs focusing on increasing women's autonomy in making home decisions should be established. Furthermore, long-term interventions for improving home SES and effective nutritional methods should be examined.

Author Contributions: A.M.A. and M.A.: statistical analysis, manuscript preparation; F.J.: performed measurements, manuscript preparation; C.C.: manuscript review; O.S.B.: study design, manuscript review; A.M.A.: study design, control measurements, manuscript review; M.A. and F.J.: study design, manuscript review, project Administration. All authors have read and agreed to the published version of the manuscript.

Funding: This manuscript is supported by Digiteknologian TKI-ymparisto project A74338 (ERDF, Regional Council of Pohjois-Savo).

Institutional Review Board Statement: Not applicable.

Informed Consent Statement: Not applicable.

Data Availability Statement: Data used in this manuscript can be freely accessed through "measuredhs.com" (accessed on 14 August 2021) after registration and permission.

Acknowledgments: The authors warmly thank the referees for their useful comments.

Conflicts of Interest: The authors declare that they have no conflict of interest to report regarding the publication of this study.

Ethical Approval: This study did not require ethical approval as a secondary data analysis was performed using PDHS data for year 2012-2013. Data were obtained from measuredhs.com (accessed on 14 August 2021) after permission. PDHS data are collected with due ethical considerations. Anybody can access the data after getting registered on measuredhs.com (accessed on 14 August 2021).

\section{References}

1. Pakistan Demographic and Health Survey; Final Report. 2013. Available online: http://www.nips.org.pk/abstract_files/PDHS\% 20Final\%20Report\%20as\%20of\%20Jan\%2022-2014.pdf (accessed on 14 August 2021).

2. Endris, N.; Asefa, H.; Dube, L. Prvalence of Malnutrition and Associated Factors among Children in Rural Ethopia. Biomed Res. Int. 2017. [CrossRef]

3. World Health Organization: UNICEF-WHO-The World Bank: Joint Child Malnutrition Estimates. 2017. Available online: https:/ / www.who.int/nutgrowthdb/estimates/en (accessed on 14 August 2021).

4. Achadi, E.; Ahuja, A.; Bendech, M.A.; Bhutta, Z.A.; De-Regil, L.M.; Fanzo, J.; Fracassi, P.; Grummer Strawn, L.M.; Haddad, L.J.; Hawkes, C.; et al. Global Nutrition Report 2016: Frompromise to Impact: Ending Malnutrition by 2030; International Food Policy Research Institute(IFPRI): Washington, DC, USA, 2016.

5. Raju, D.; D'souza, R. Child Under Nurtition In Paksitan: What Do We Know? World Bank: Washington, DC, USA, 2017.

6. Tariq, J.; Sajjad, A.; Zakar, R.; Zakar, M.Z.; Fischer, F. Factors Associated with Undernutrition in Children under the Age of Two Years: Secondary Data Analysis Based on the Pakistan Demographic and Health Survey 2012-2013. Nutrients 2018, 10, 676. [CrossRef] [PubMed]

7. Chowdhury, M.R.; Rahman, M.S.; Khan, M.M.; Mondal, M.N.; Rahman, M.M.; Billah, B. Risk Factors of Child Malnutrition in Bangladesh: A Multilevel Analysis of a Nationwide Population-Based Survey. J. Pediatrics 2016, 172, 194-201.e1. [CrossRef]

8. Fentahun, N.; Balachew, T.; Lachat, C. Determinants and Mobidities of Multiple Anthropometric Deficits in Southwest Rural Ethopia. Nutrition 2016, 32, 1243-1249. [CrossRef] [PubMed]

9. Cesare, M.D.; Bhatti, Z.; Soofi, S.B.; Fotunate, L.; Ezzati, M.; Bhutta, Z.A. Geographical and Socioeconomic Inequalities in Women and Children's Nutritional Status in Paksitan in 2011: An Analysis of Data from a Nationally Representative Survey. Lancet Glob. Health 2015, 3, E229-E239. [CrossRef]

10. Alemayehu, M.; Tinsae, F.; Haileslassie, K.; Seid, O.; Gebregziabher, G.; Yebyo, H. Undernitriton Status and Associated Factors in under 5 Children in Tigray, Northern Ethopia. Nutriton 2015, 31, 964-970.

11. Khan, R.E.; Raza, M.A. Child Nutrition in Developing Countries: A Case Study Of Bangladesh. Qual. Qunatiity 2014, 48, 1389-1408. [CrossRef]

12. Svedberg, P. Poverty and Undernutrition: Theory, Measurement, and Policy; Oxford University Press: Oxford, UK, 2000. 
13. Sen, J.; Mondal, N. Socio-Economic and Demographic Factors Affecting the Comoposite Index Anthropometric Filure (Ciaf). Ann. Hum. Biol. 2012, 39, 129-136. [CrossRef]

14. Khan, R.E.; Azid, T. Malnutrition in Primary School-Age Children: A Case of Urban and Slum Areas of Bahawalpur, Pakistan. Int. J. Soc. Econ. 2011, 38, 748-766. [CrossRef]

15. Das, S.; Bose, K. Assesment of Nutritional Status by Anthropometric Indices in Santal Tribal Children. J. Life Sci. 2011, 3, 81-85. [CrossRef]

16. World Health Organization. WHO Child Growth Standards: Length/Height-for-Age, Weight-for-Age, Weight-for-Length, Weight-forHeight and Body Mass Index-for-Age: Methods and Development; World Health Organization: Geneva, Switzerland, 2006.

17. Nandy, S.; Irving, M.; Gordon, D.; Subramanian, S.; Smith, G.D. Poverty, Child Udernutrition and Morbidity: New Evidence From India. Bull. World Health Organ. 2005, 83, 210-216.

18. United Nations Children's Fund. Strategy for Improved Nutrition of Children and Women in Developing Countries. A UNICEF Policy Review; ERIC Clearinghouse: New York, NY, USA, 1990.

19. Rutstein, S. Wealth Versus Expenditure: Comparison between the DHS Wealth Index and Household Expenditures in Four Departments of Guatemala; ORC Macro: Calverton, MD, USA, 1999.

20. Sahn, D.E.; Stifel, D. Exploring Alternative Measure of Welfare in the Absence of Expenditure Data. Rev. Income Wealth 2003, 49, 463-489. [CrossRef]

21. Gunther, I.; Fink, G. Water, Sanitation and Children's Health: Evidence from 172 DHS Surveys; The World Bank: Washington, DC, USA, 2010

22. Hosmer, D.M.; Lemeshow, S.; Sturdivant, R.X. Applied Logistic Regression; John Willy and Sons: Hoboken, NJ, USA, 2013.

23. Hilbe, J.M. Logistic Regression Models; Capman and Hall/Crc: New York, NY, USA, 2009.

24. Dasgupta, A.; Sahoo, S.K.; Tarafdar, P.; Pareeti, P.; Biswas, D.; Kumar, A.; Sarkar, I. Composit Index Anthropometic Failure and Its Important Correlates: A Study among Under-5 Children in A Slum of Kolkata, West Bengal, India. Int. J. Med Sci. Public Health 2015, 4, 414-419. [CrossRef]

25. Tsague, G.N.; Dapi, L.N. Multidimensional Natue of Undernutrition: A Statistical Approach. J. Med. Med. Sci. $2011,2,690-695$.

26. Gupta, A.K.; Borkotoky, K. Exploring the Mltidimentional Nature of Anthropometric Indicators for under-Five Children in Indial. Indian J. Public Health 2016, 60, 68-72. [CrossRef]

27. Khan, R.E.; Raza, M.A. Determinants of Malnutrition in Indian Children: New Evidnece from Idhs Through Ciaf. Qual. Quant. 2016, 50, 299-326. [CrossRef]

28. Petrou, S.; Kupek, E. Poverty And Child Undernutrition in Devolping Countries: A Multi-National Chohort Study. Soc. Sci. Med. 2010, 71, 1366-1373. [CrossRef]

29. Kandala, N.-B.; Madungu, T.P.; Emina, J.B.; Pdnzita, K.; Cappuccio, F.P. Malnutrition Among Children under the Age of Five in Democratic Republic of Congo (Drc): Does Geographic Location Matter? BMC Public Health 2011, 11, 261. [CrossRef] [PubMed]

30. Arif, G.M.; Nazir, S.; Satti, M.N.; Farooq, S. Child Malnutrition in Pakistan: Trends and Determinants. Pak. Inst. Dev. Econ 2012, 2012,1-8. Available online: https:/ /www.pide.org.pk/pdf/Working\%20Paper/Child\%20Malnutrition\%20.pdf (accessed on 1 November 2021).

31. Mushtaq, M.U.; Gull, S.; Khurshid, U.; Shahid, U.; Shad, M.A.; Siddiqui, A.M. Prevalance and Socio-Demographic Correlates of Stunting and Thinness Among Pakistani Primary School Children. Bmc Public Health 2011, 11, 790.

32. Altare, C.; Delbiso, T.D.; Mutwiri, G.M.; Kopplow, R.; Guha-Sapir, D. Factors Associated with Stunting Among Pre-School Children in Southern Hihglands of Tanzania. J. Trop. Pediatrics 2016, 62, 390-408. [CrossRef]

33. Poda, G.G.; Hsu, C.-Y.; Chao, H.C. Factors Associated with Manutrition among Children <5 Years Old in Burkina Faso: Evidence from the Demografic and Health Survey Iv 2010. Int. J. Qual. Health Care 2017, 29, 901-908. [CrossRef]

34. Akombi, B.J.; Agho, K.E.; Hall, J.J.; Merom, D.; Astell-Burt, T.; Renzaho, A.M. Stunting and Sever Stunting among Children Under-5 in Nigeria: A Multilevel Analysis. BMC Pediatrics 2017, 17, 15. [CrossRef]

35. Rahman, M.M.; Saima, L.G.; Abdu, M. Impact of Maternal Household Dexision-Mking Autonomy on Child Nutritional Status in Bangladesh. Asia-Pac. J. Public Health 2015, 27, 509-520. [CrossRef]

36. Asena, T.F.; Teni, D.A. Bayesian Semi-Parametric Regression Analysis of Childhood Malnutrition in Gamo Gofa Zone: The Social and Economic Impact of Child Malnutrition. Am. J. Theor. Appl. Stat. 2015, 4, 269-276. [CrossRef]

37. Frongillo, E.A.; Onis, M.D.; Hanson, K.M. Socioeconomic and Demographic Factors Are Associated with World Wide Patterns of Stunting and Wasting of Children. Community Int. Nutr. 1997, 127, 2302-2309.

38. Solanki, R.; Patel, T.; Shah, H.; Singh, U.S. Meansuring Undernutrition through Z-Scores and Composite Idex of Anthropometric Failure(Ciaf): A Study among Slum Children in Ahmadabad City, Gujrat. Natl. J. Community Med. 2014, 5, 434-439.

39. Asif, A.M.; Tahir, M.R.; Arshad, I.A. Socioeconomic Condition and Prevalence of Malaria Fever in Pakistani Children: Findings from a Community Health Survey. J. Trop. Pediatrics 2017, 64, 189-194. [CrossRef]

40. Darteh, E.K.; Acquah, E.; Kumi-Kyereme, A. Correaltes of Stunting among Children in Ghana. BMC Public Health 2014, 14, 504. [CrossRef] [PubMed] 
41. Sarma, H.; Khan, J.R.; Asaduzzaman, M.; Uddin, F.; Tarannum, S.; Hasan, M.M.; Rahman, A.S.; Ahmed, T. Factors Influencing the Prevelance of Stunting among Children Aged below Five Years in Bangladesh. Food Nutr. Bull. 2017, 38, 291-301. [CrossRef] [PubMed]

42. Hatt, L.; Waters, H.R. Determiants of Child Morbidity in Latin America: A Pooled Analysis of Interactions between Parental Education and Economic Status. Soc. Sci. Med. 2006, 62, 375-386. [CrossRef] 